\title{
Broad Ligament Pregnancy: A Rare Case Report
}

\author{
MARUF SIDDIQUI ${ }^{1}$, NUSRAT GHAFOOR ${ }^{2}$, FAHMIDA NAZNINE ${ }^{3}$, \\ RUSMILA SHAMIM ABDULLAH ${ }^{4}, \mathrm{~T}^{2}$ A CHOWDHURY ${ }^{5}$
}

\begin{abstract}
:
Broad ligament pregnancy is a rare obstetric condition. Its diagnosis is quite difficult and management is challenging. Here we report a case of a 26 years old primi gravida conceived following laparoscopy and ovulation induction. Diagnosis of the broad ligament pregnancy was done by a transvaginal ultrasound at her 9 weeks and was proceded with laparoscopy followed by laparotomy. A right broad ligament pregnancy was found and the sac with fetus was removed. Laparoscopy was converted into a laparotomy as there was an uncontrollable bleeding from the broad ligament. Here we present a case of this extreme rare type of broad ligament pregnancy.
\end{abstract}

Key words: Broad Ligament, Ectopic, Transvaginal Ultrasound, Laparoscopy

\section{Introduction:}

Broad ligament pregnancy is a rare but potentially fatal type of ectopic pregnancy. It is considered as a kind of abdominal pregnancy with the gestational tissue implanted between the two layers of the broad ligament ${ }^{1,2,3}$. It has a reported incidence of 1 in $1,83,900$ pregnancies and occurs in about 1 in 245 ectopic pregnancies ${ }^{3}$. The clinical presentation of broad ligament pregnancy is highly variable and can range from asymptomatic ectopic pregnancy to rupture in labor at term. Accurate preoperative diagnosis is often difficult. Laparoscopy / laparotomy for broad ligament pregnancy is among the most difficult and dangerous operations as severe uncontrollable hemorrhage occurs during the separation of the placenta ${ }^{4}$. This is a case of broad ligament pregnancy in which laparoscopy followed by laparotomy had to be done to remove the sac and to control excessive bleeding.

\section{Case report:}

A 36 years old lady presented to the OPD of Department of Infertility and Reproductive Medicine, Anwer Khan Modern Medical College with the complaints of primary Subfertility. During laparoscopy dye passed freely from both the tubes following passage of large amount of mucous sludge. Following laparoscopy ovulation induction was given and luckily the patient conceived and was referred to a local doctor. The patient presented to us again at 9 weeks of pregnancy with a complain that the local sonologists were unable to detect any intrauterine sac though the pregnancy test was positive. A Trans vaginal ultrasound in our OPD of infertility department detected a 9 weeks live pregnancy sac on the right adnexal region with an empty uterus (Figure $1 \& 2$ ). Color Doppler showed an increased vascularity and aroused the suspicion of a right sided broad ligament pregnancy (Figure 3 ). So a decision of laparoscopy, if needed a laparotomy, was taken with informed consent from the patient. As soon as the $10 \mathrm{~mm}$ central umbilical port was made, the telescope detected a pregnancy sac attached to the posterior leaf of right broad ligament. The sac along with the fetus was removed but uncontrollable bleeding started when attempt was made to remove the placental tissue. Both monopolar and bipolar diathermy were used but they were

1. Associate Professor \& Head, Dept. of Infertility \& Reproductive Medicine, Anwer Khan Modern Medical College

2. Associate professor \& Consultant, Dept. of Radiology \& Imaging, Ibrahim Cardiac Hospital \& Research Institute(ICHRI)

3. Assistant Registrar, Dept. of Infertility \& Reproductive Medicine, Anwer Khan Modern Medical College

4. Medical Officer, Dept. of Infertility \& Reproductive Medicine, Anwer Khan Modern Medical College

5. Chief Consultant and Professor of Obstetrics \& Gynaecology, Ibrahim Medical College \& BIRDEM Hospital

Address of correspondence: Dr. Maruf Siddiqui, Associate Professor \& Head, Dept. of Infertility \& Reproductive Medicine, Anwer Khan Modern Medical College. Email: drmaruf2000@yahoo.com, Mobile: 01711593978 


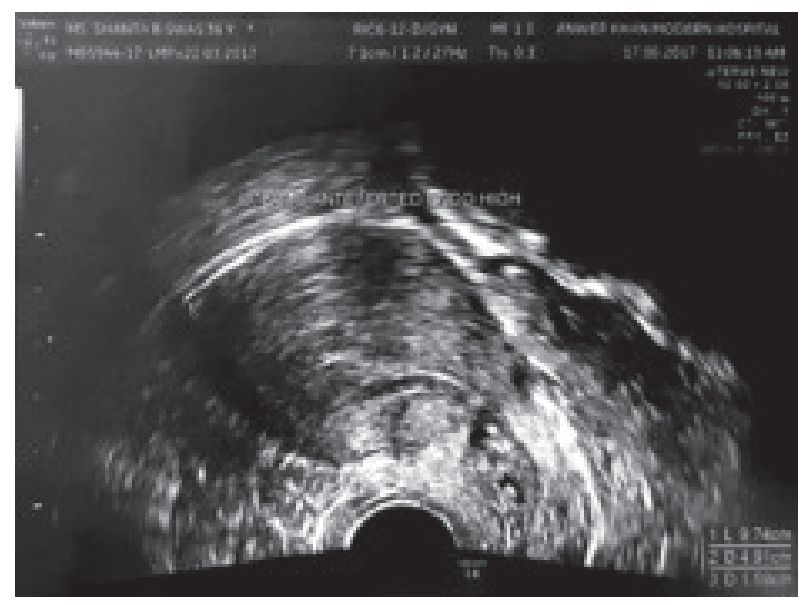

Fig.-1: USG showing an empty uterus

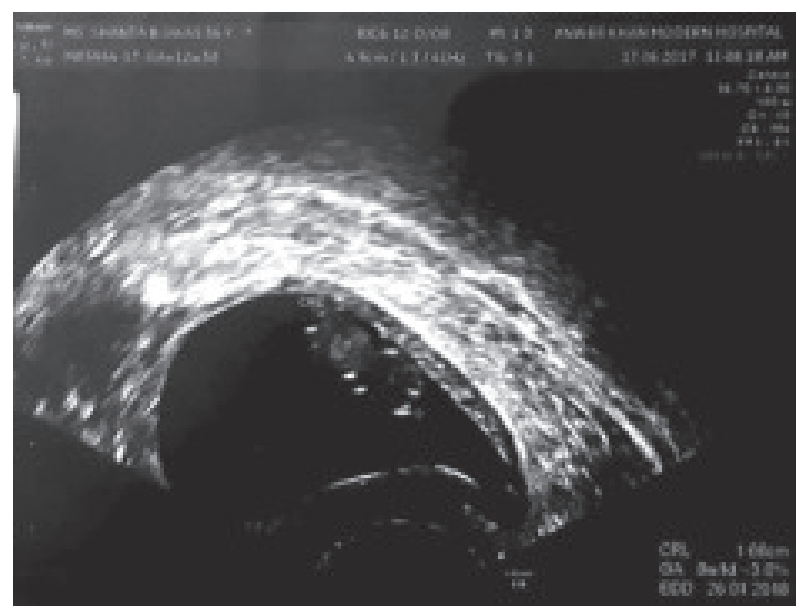

Fig.-2: USG showing an alive ectopic sac in the broad ligament

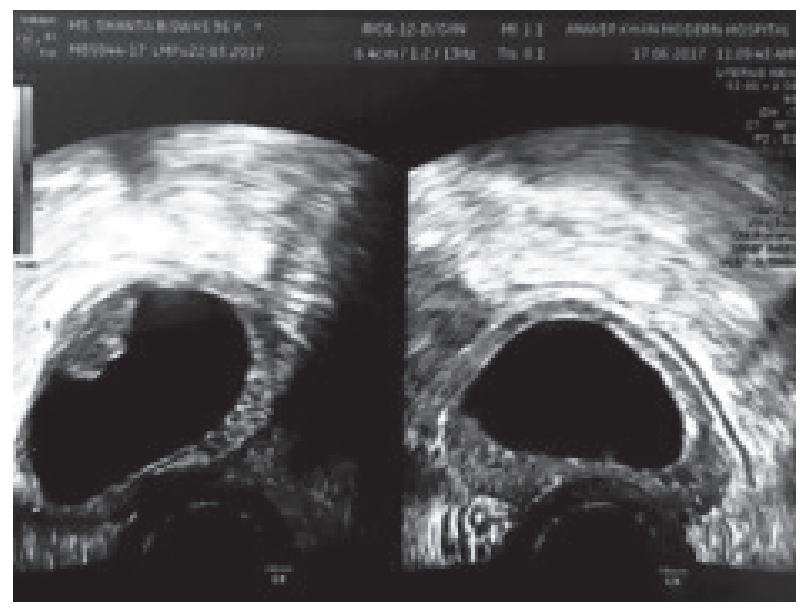

Fig.-3: USG color Doppler showing increased vascularity in the broad ligament unable to control the bleeding. Laparoscopy was abandoned in favor of laparotomy and the bleeding was controlled effectively. Two units of blood were transfused during the procedure. The postoperative period was uneventful and the patient was discharged at third postoperative day.

\section{Discussion:}

Broad ligament ectopic pregnancy is a rare but life threatening condition and accounts for 1 percent of ectopic pregnancies. Maternal mortality is as high as 20 percent ${ }^{5}$.It is either due to primary implantation of the zygote on the broad ligament or followed by secondary implantation to fallopian tube, ovary or other peritoneal surface.

The risk factors include a history of pelvic inflammatory disease, use of an intra-uterine device, endometriosis and pelvic tuberculosis. However there were no apparent risk factors in our case.

The clinical presentation of broad ligament ectopic pregnancy is highly variable and can range from asymptomatic early ectopic pregnancy to rupture in labour at term. Dull lower abdominal pain during early gestation is common. This has been attributed to the placental separation, tearing of broad ligament and small peritoneal haemorrhage $e^{6,7}$. Vaginal bleeding is also a common feature repoted in upto half of the patients ${ }^{8}$.

Most of the cases of broad ligament pregnancies are sometimes difficult to diagnose. The advancement of high resolution transvaginal sonograghy combined with serum beta-HCG can now diagnose most of the cases very accurately. Interestingly many of the cases were diagnosed during operation. Magnetic Resolution Imaging(MRI) provides additional information for evaluating the extent of uterine and mesenteric involvement ${ }^{9}$.

The management is exploratory laparotomy. However, stable patients with early gestation can be considered for laparoscopic removal for small broad ligament pregnancies ${ }^{10}$. In our case laparoscopy was initially attempted as the patient was stable. But later on laparoscopy was converted to laparotomy to control brisk hemorrhages following removal of the placenta.

Mortality due to massive hemorrhage from ruptured abdominal pregnancy has been well recognized because of the difficulty in making an early diagnosis. Similarly, pregnancy between the broad ligaments 
can lead to significant maternal morbidity and even mortality. The most common complication was rupture resulting in hemoperitoneum. Most broad ligament ectopic pregnancies could not reach fetal viability.

The key to the management of broad ligament ectopic pregnancy involves a high index of suspicion, early diagnosis and prompt surgery.

\section{References:}

1. Cordero DR, Adra A, Yasin S, O'Sullivan MJ. Intraligamentary pregnancy. Obstet Gynecol Surv. 1994;49(3):206 -209.

2. Phupong V, Lertkhachonsuk R, Triratanachat $\mathrm{S}$, Sueblinvong T. Pregnancy in the broad ligament. Arch Gynecol Obstet. 2003;268(3):233-235.

3. Chia KV, Fayle RJS, Ferriman E. Intraligamentary pregnancy.J Obstet Gynaecol. 1993;13:254.

4. Marriott C. Specimen from case of extra-uterine pregnancy. Proceedings of the Royal Society of Medicine; 1919;12.
5. S Sharma, N Pathak, SPS Goraya, P Mohan. Broad ligament ectopic pregnancy. Srilanka Journal of Obstetrics and Gynaecology. 2011;33:60-62

6. Peterson WG, Grant KA. Advanced Intraligamentous pregnancy. Report of a case, Review of the literature and a discussion of the biological implications. Obstet Gynecol Surv. 1975;30:715-26.

7. Vierhout ME, Wallenburg HC. Intraligamentary pregnancy resulting in a live infant. Am J Obstet Gynecol. 1985:152:878-9.

8. Hallatt JG, Grove JA. Abdominal pregnancy: a study of twenty-one consecutive cases. Am J Obstet Gynecol. 1985;152:444-9.

9. Mittal S et al. Brood ligament ectopic pregnancy: a dialemma to diagnose Int J Reprod Contrcept Obstet Gynecol. 2017 May;6(5):2109-2111.

10. Piskar MD Casson PR, Moise KJ, Di Maio DJ, Buster JE, Carson SA. Heterotropic abdominal pregnancy treated at laparoscopy. Fertil Steril. 1998;70:159-60. 